\title{
Apoptotic potential of the concentrated effective microorganism fermentation extract on human cancer cells
}

\author{
CHUNG HIN CHUI ${ }^{1,2^{*}}$, DESMOND KWOK PO HAU ${ }^{3 *}$, FUNG YI LAU ${ }^{2 *}$, GREGORY YIN MING CHENG ${ }^{2}$, \\ RAYMOND SIU MING WONG ${ }^{2}$, ROBERTO GAMBARI ${ }^{4}$, STANTON HON LUNG KOK ${ }^{1}$, KA BIK LAI $^{2}$, \\ IVY TUANG NGO TEO ${ }^{1}$, THOMAS WAI TONG LEUNG ${ }^{5}$, TERUO HIGA ${ }^{6}$, BIN KE $^{7}$, \\ JOHNNY CHEUK ON TANG ${ }^{1}$, DAVID WAN FUN FONG ${ }^{3}$ and ALBERT SUN CHI CHAN ${ }^{1}$
}

\begin{abstract}
${ }^{1}$ Anti-Cancer Research Center, Central Laboratory of the Institute of Molecular Technology for Drug Discovery and Synthesis, State Key Laboratory of Chinese Medicine and Molecular Pharmacology, Department of Applied Biology and Chemical Technology, The Hong Kong Polytechnic University; ${ }^{2}$ Department of Medicine and Therapeutics,

Prince of Wales Hospital, The Chinese University of Hong Kong; ${ }^{3}$ Department of Biology and Chemistry,

The City University of Hong Kong, Hong Kong, P.R. China; ${ }^{4}$ ER-GenTech, Department of Biochemistry and Molecular Biology, Section of Molecular Biology, University of Ferrara, Italy; ${ }^{5}$ Oncology Centre,

The Hong Kong Sanatorium and Hospital, Hong Kong, P.R. China; ${ }^{6}$ Faculty of Agriculture,

University of the Ryukyus; ${ }^{7}$ EM Research Organization, Okinawa, Japan
\end{abstract}

Received September 19, 2005; Accepted November 18, 2005

\begin{abstract}
The effective microorganism fermentation extract (EM-X, the first generation) was claimed to possess strong anti-oxidation property. On the other hand, we have shown that the second generation of the effective microorganism fermentation extract (EM-X2) possessed growth inhibition on human cancer cells involving MDA-MB231 breast cancer and K-562 chronic myelogenous leukaemia cells. Elevation of super oxide dismutase activity from EM-X2 treated cancer cell extract was observed. However, the possible anti-cancer activity of the first generation of the EM-X was not reported. Here we demonstrate that the concentrated form of the EM-X from its original fluid also possess antiproliferation ability together with induction of apoptosis on the human cancer cell lines including Hep3B hepatocellular carcinoma (HCC) and
\end{abstract}

Correspondence to: Professor Gregory Yin Ming Cheng, Department of Medicine and Therapeutics, Prince of Wales Hospital, The Chinese University of Hong Kong, Ngan Shing Street, Sha Tin, Hong Kong, P.R. China

E-mail: gcheng@cuhk.edu.hk

Dr Johnny Cheuk On Tang, Department of Applied Biology and Chemical Technology, The Hong Kong Polytechnic University, Hung Hom, Kowloon, Hong Kong, P.R. China

E-mail: bccotang@inet.polyu.edu.hk

${ }^{*}$ Contributed equally

Key words: acute myelogenous leukaemia, effective microorganism fermentation extract, hepatocellular carcinoma
KG1a acute myelogenous leukaemia (AML). Similar effect could also be demonstrated on primary cultured bone marrow samples isolated from patients with AML. Morphological inspection revealed that common apoptotic feature was found on these concentrated EM-X treated cancer cells. Both the anchorage-dependent clonogenicity assay on Hep3B HCC and methyl-cellulose colony formation assay on KG1a cells and bone marrow cells from AML patients further revealed the ability of the concentrated EM-X on reducing their colony formation ability. Incubating KG1a with concentrated EM-X readily induced apoptosis as demonstrated by flow cytometric analysis. Interestingly, few growth inhibition effect of the concentrated EM-X was observed on both the SV40 transformed THLE-2 liver epithelial cells and primary cultured non-malignant haematological disordered bone marrow. Collectively, this concentrated EM-X is effective in inducing cell death and reducing the regeneration potential of both Hep3B HCC and KG1a AML cells in vitro.

\section{Introduction}

Among East Asia, the rate of occurrence of hepatocellular carcinoma (HCC) is relatively high. Many factors including hepatitis $\mathrm{B}$ infection and liver cirrhosis increase the rate of HCC formation. There are about 350 million hepatitis B carriers around the world, of whom about $75 \%$ are found in East Asia. The chance of developing HCC in patients with hepatitis B is nearly 100-fold greater than for those without inflection. On the other hand, intake of alfatoxin also favours HCC formation. Crops including fermented peanuts are believed to be rich in alfatoxin. Leukaemogenesis also involves numerous factors. Environmental pollution is said to play an important role. 
The effective microorganisms fermented extract (EM-X, the first generation) is a refreshment drink commonly found in East Asia. This is produced by fermentation of papaya, seaweed extract and rice bran using effective microorganisms such as photosynthetic bacteria, lactic acid bacteria and yeast. EM-X is rich in $\alpha$-tocopherol, flavonoids, lycopene, minerals, saponin and ubiquinone. A report from chemical analysis suggests that EM-X is negative in amphetamines, opiatos, methadone, cocaine, cannabinoids and benzodiazepinos. The level of heavy metals including mercury and cadium are also much below the maximum contaminant level in drinking water as recommended by United States Environmental Protection Agency. It is also negative for $E$. coli contamination. Recently, we have demonstrated the growth inhibitory activity of the secondary generation of EM-X (EM-X2) on breast cancer MDA-MB231 and chronic myelogenous leukaemia K-562 cell lines (1). Elevation of super oxide dismutase activity from EM-X2 treated cancer cell extract was observed. However, the possible anti-cancer activity of EM-X was not reported. Here we demonstrate that the concentrated form of the EM-X from its original fluid (standard fluid) also possess antiproliferation ability together with induction of apoptosis on the human cancer cell lines including Hep3B hepatocellular carcinoma (HCC) and KG1a acute myelogenous leukaemia (AML).

\section{Materials and methods}

Preparation of concentrated $E M-X$. The original pale greenish fluid of EM-X was mixed with absolute ethanol. The mixture was then warmed in a round bottomed flask using a rotatory evaporator in a warm water bath. When all fluid was evaporated, the net weight of the dried extract that remained was measured. The volume of fluid from each step was also recorded. The dried extract was then dissolved in sterile distilled water to a final concentration of $20 \mathrm{mg} / \mathrm{ml}$. The concentrated EM-X was further filtered in a $0.22 \mu \mathrm{m}$ filter. The filtrate was then stored in aliquots at $-20^{\circ} \mathrm{C}$ until use.

Cell lines and cell culture. The cell lines employed in this study included the hepatocellular carcinoma origin Hep3B, liver adenocarcinoma SK-Hep-1, the SV40 transformed liver epithelial THLE-2 cells and the acute myelogenous leukaemia KG1a. They were obtained from American Type Culture Collection and maintained routinely in minimum essential medium (MEM) cell culture (JRH BioSciences) supplemented with $5 \%$ fetal bovine serum (Hyclone) together with penicillin and streptomycin (Invitrogen) in a 5\% carbon dioxide humidified incubator at $37^{\circ} \mathrm{C}$.

Primary cultures from AML and non-malignant bone marrow. After informed consent, bone marrow samples were obtained from two patients with de novo AML and two patients with non-malignant haematological disorder. Mononuclear cells were enriched and harvested immediately after Ficoll density centrifugation (General Electricity, Amersham) and washed with phosphate buffered saline (PBS). Cell pellets were resuspended in RPMI-1640 culture medium and cell viability was determined by trypan blue exclusion assay.
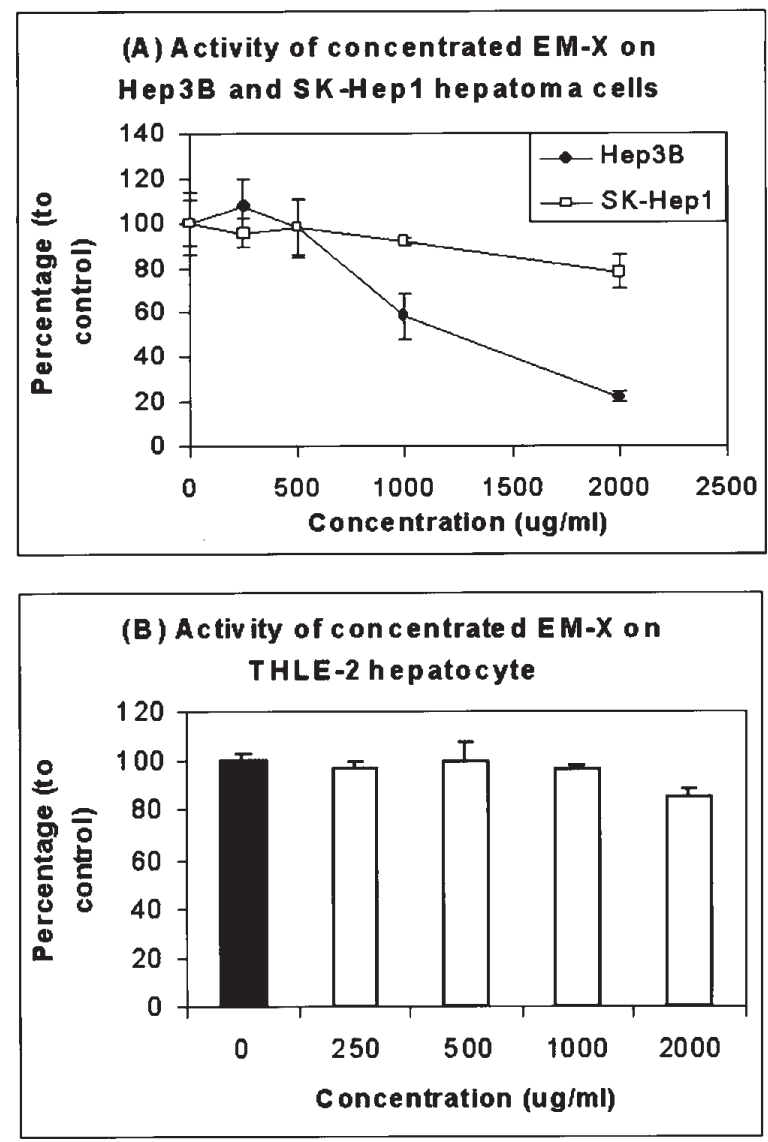

Figure 1. Cytotoxicity of concentrated EM-X on Hep3B hepatocellular carcinoma cell and SK-Hep-1 liver adenocarcinoma (A) and SV40 transformed liver epithelial THLE-2 cells (B). After 48-h incubation in the presence of the indicated concentrations of concentrated EM-X, the percentage of cell viability was measured as described in the Materials and methods. Results are shown as mean \pm SD of triplicate experiments. A representative result of three independent experiments is shown.

Antiproliferative and cytotoxic tests. The 1-step ATP Lite luminescence kit purchase from Perkin Elmer was used to test the antiproliferative and cytotoxic activites of concentrated EM-X. Briefly, different cells were seeded in a 96well microtitre plate on the first day. The second day, growth medium was changed and different concentrations of the concentrated EM-X [starting from $10 \%(\mathrm{v} / \mathrm{v})$ by volume ratio, thus effective concentration started from $2 \mathrm{mg} / \mathrm{ml}$ ] was added. In each case, $10 \%(\mathrm{v} / \mathrm{v})$ of sterilized water was used as control while the concentrated EM-X was serially diluted with sterile distilled water so that water would always contribute to $10 \%(\mathrm{v} / \mathrm{v})$ of final volume. After $48 \mathrm{~h}$, the resulting luminescence from water control and concentrated EM-X treated cells were measured using a $\operatorname{Victor}^{2} \mathrm{~V}$ multilabel 1420 counter (Perkin Elmer) according to the instruction manual provided.

Morphological changes of EM-X treated cell. Cancer cells were seeded as mentioned before and then $2 \mathrm{mg} / \mathrm{ml}$ of concentrated EM-X was added. Any morphological changes after $48 \mathrm{~h}$ were observed under an inverted microscope.

Colony formation assay of hepatocellular carcinoma Hep3B cell. The cancer cell line Hep3B was incubated with 5\% (v/v) 

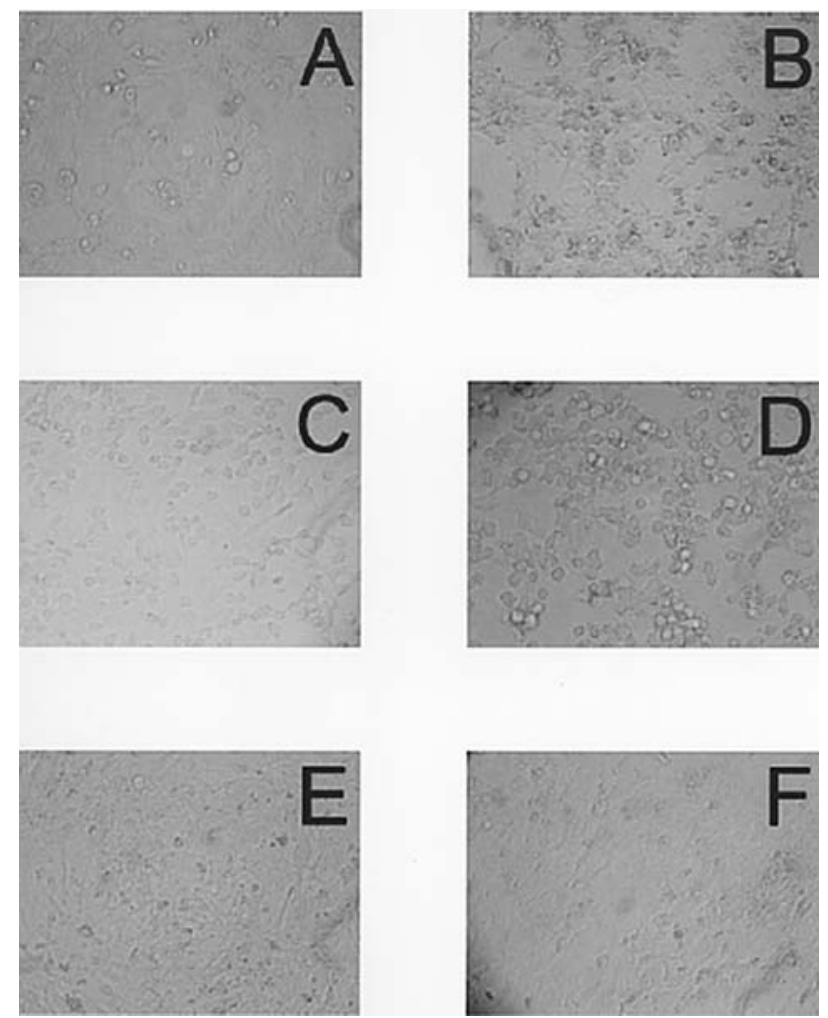

Figure 2. Morphological investigation on hepatocellular carcinoma, liver adenocarcinoma and SV40 transformed liver epithelial cells after 48-h treatment with $2 \mathrm{mg} / \mathrm{ml}$ of EM-X. Hep3B (A and B), SK-Hep-1 (C and D) and SV40 transformed liver epithelial THLE-2 cells (E and F) were treated with vehicle (A, C and E) or with $10 \%$ (v/v) concentrated EM-X (B, D and F).

of concentrated EM-X (thus $1 \mathrm{mg} / \mathrm{ml})$ plus $5 \%(\mathrm{v} / \mathrm{v})$ sterile distilled water or $10 \%(\mathrm{v} / \mathrm{v}$ ) of concentrated EM-X (thus $2 \mathrm{mg} /$ $\mathrm{ml}$ ) for 6 days. Untreated control cells were incubated with $10 \%(\mathrm{v} / \mathrm{v})$ of sterile distilled water only for 6 days. Afterwards, culture plates were washed, stained with methylene blue, washed again, and then recorded photographically.

Colony formation assay of KGla and bone marrow cells. KG1a AML cells and mononuclear cells isolated from bone marrow samples were counted and cultured in methylcellulose (Stemcell Technonolgy, Canada) with either vehicle or $2 \mathrm{mg} / \mathrm{ml}$ of concentrated EM-X for 14 days. Viable colony formation units (CFU) could reduce 3-(4,5-dimethylthiazoyl)2,5-diphenyltetrazolium bromide (MTT) were then scored under an inverted microscope.

Flow cytometric analysis. KG1a AML cells were treated with $2 \mathrm{mg} / \mathrm{ml}$ of concentrated EM-X for $24 \mathrm{~h}$. Afterwards, cells were washed with PBS and then fixed with ice-cold $70 \%$ ethanol. After washing with PBS again, cells were resuspended in PBS with $50 \mu \mathrm{g} / \mathrm{ml}$ propidium iodode and $100 \mu \mathrm{g} / \mathrm{ml}$ RNase. Propidium iodide stained cells were further analysed by the CellQuest software using a Becton-Dickinson FACS flow cytometer. The percentage of KG1a cells falling into the sub- $\mathrm{G}_{0} / \mathrm{G}_{1}$ population was considered as 'apoptotic' and counted.
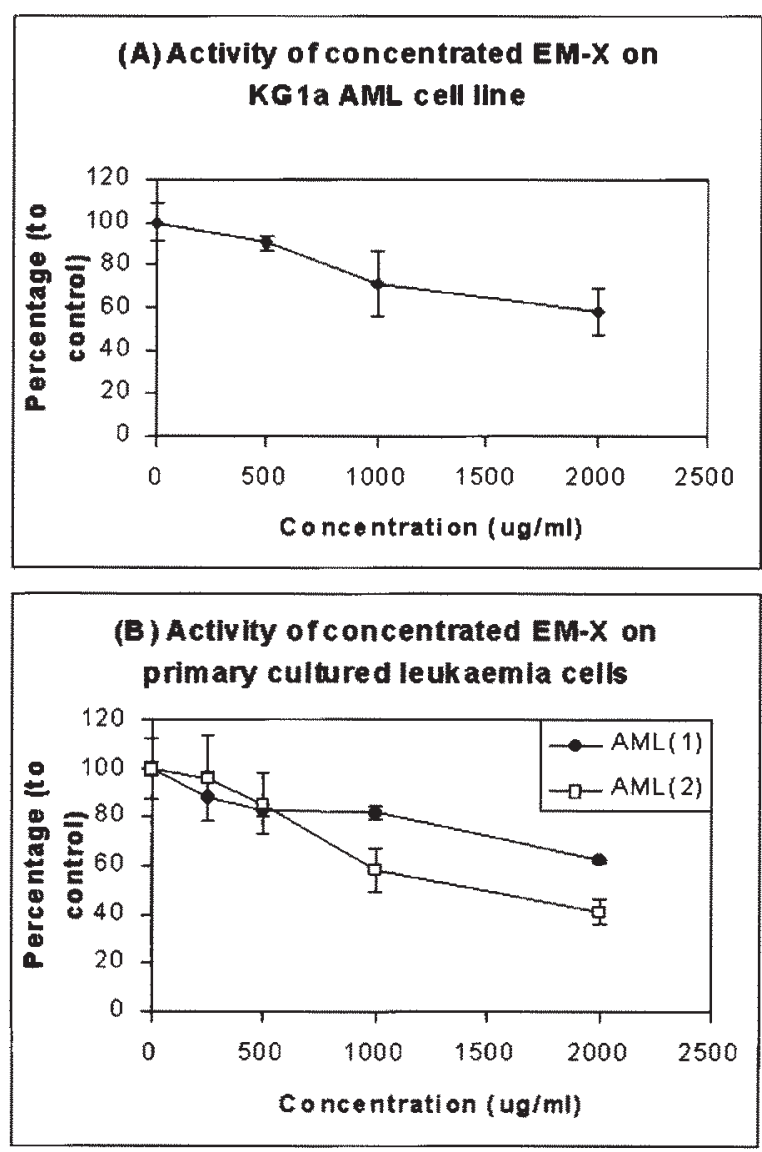

Figure 3. Cytotoxicity of concentrated EM-X on KG1a acute myelogenous leukaemia (AML) cells (A) and primary cultured leukaemia cells from two de novo AML patients (B). After 48-h incubation in the presence of the indicated concentrations of concentrated EM-X, the percentage of cell viability was measured as described in the Materials and methods. Results are shown as mean $\pm \mathrm{SD}$ of triplicate experiments. A representative result of three independent experiments is shown.

\section{Results}

Effects of concentrated EM-X on HCC and SV4O transformed liver epithelial cells. Concentrated EM-X solution effectively exerted antiproliferative and cytotoxic effects on the Hep3B HCC cell line (Figs. 1A and 2). For SK-Hep-1 liver adenocarcinoma, growth inhibitory activity (Fig. 1A) plus mild apoptotic action as shrinkage and rounding of cells was observed (Fig. 2). For the SV40 transformed THLE-2 liver epithelial cells, only weak growth inhibitory action could be detected (Fig. 1B) and no evidence of cytotoxicity was observed (Fig. 2).

Effects of concentrated EM-X on the AML cell line and primary cultured bone marrow cells. The concentrated EM-X solution significantly inhibited growth of the KG1a AML cell line together with the bone marrow samples isolated from two AML patients (Fig. 3). At higher dosage (2 mg/ml), significant growth inhibition plus cell death induction including cell shrinkage was demonstrated on both KG1a and primary cultured leukaemia cells (Fig. 4). Interestingly, $2 \mathrm{mg} / \mathrm{ml}$ of concentrated EM-X have only about a mean of $20 \%$ growth inhibitory effect on non-malignant haematological disorder 

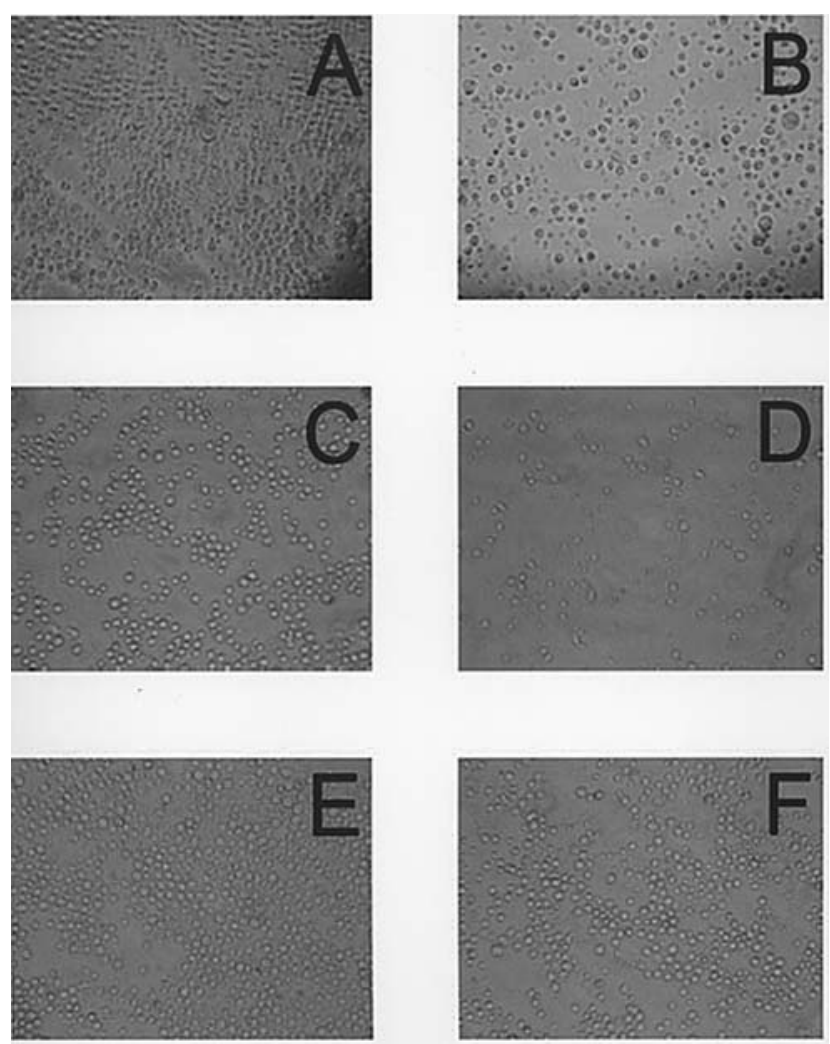

Figure 4. Morphological investigation on KG1a acute myelogenous leukaemia (AML) cell line, primary cultured AML cell and non-malignant haematological disorder bone marrow after 48-h treatment with $2 \mathrm{mg} / \mathrm{ml}$ of EM-X. KG1a (A and B), bone marrow cells from AML patient (C and D) and bone marrow cells from patient with a non-malignant haematological disorder bone marrow (E and F) were treated with vehicle (A, C and E) or with $2 \mathrm{mg} / \mathrm{ml}$ of concentrated $\mathrm{EM}-\mathrm{X}(\mathrm{B}, \mathrm{D}$ and $\mathrm{F})$.

bone marrow. There was no evidence of cell death on nonmalignant haematological disorder bone marrow cells at this dosage (Fig. 4).

Effects of concentrated EM-X on colony formation potential. After incubating both Hep3B and KG1a cells with concentrated EM-X, we analysed the effects of the concentrated EM-X on their colony formation potential. It was demonstrated that the concentrated EM-X effectively reduced their re-generation potential. A dose-dependent relation (from 0 to $1 \mathrm{mg} / \mathrm{ml}$ and then $2 \mathrm{mg} / \mathrm{ml}$ ) was found in the case of the Hep3B HCC cells (Fig. 5A). At the dosage of $2 \mathrm{mg} / \mathrm{ml}$, a complete loss of colony formation was achieved in Hep3B cells. In KG1a, a complete loss of colony formation could not be obtained, significant inhibition was found at a dose of $2 \mathrm{mg} / \mathrm{ml}$ of the concentrated EM-X (Fig. 5B).

In primary cultured bone marrow cells, the concentrated EM-X reduced the regeneration potential of bone marrow cells isolated from AML patients (Fig. 6A-C). Interestingly, 2 $\mathrm{mg} / \mathrm{ml}$ of concentrated EM-X did not exert significant inhibition of colony formation from bone marrow cells isolated from patients with a non-malignant haematological disorder (Fig. 6D).

Induction of apoptosis by concentrated EM-X on KGIa cells. Flow cytometric analysis was employed to demonstrate the
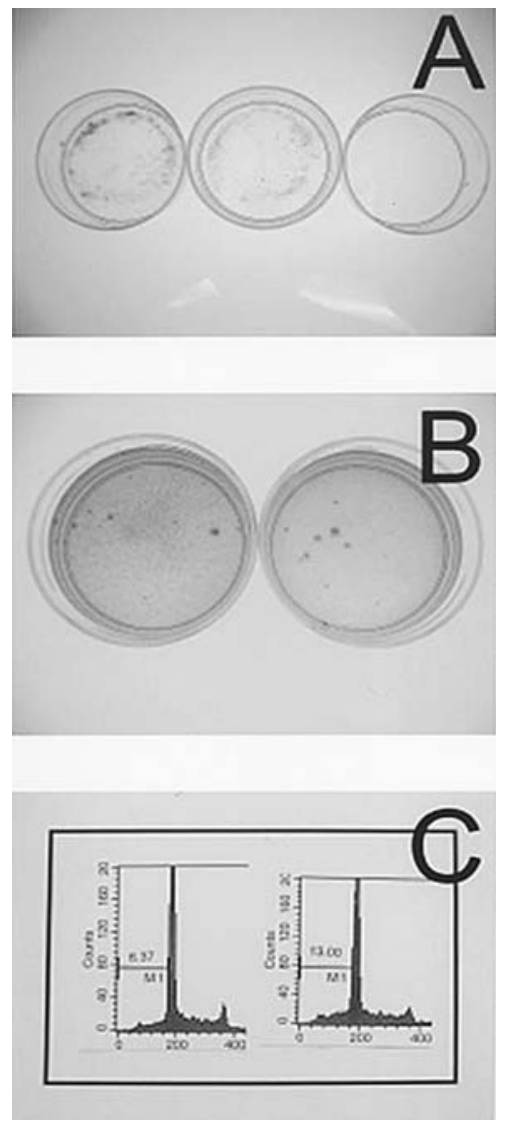

Figure 5. Effects of concentrated EM-X on the regeneration potential of Hep3B using anchorage dependent clonogenicity assay incubated with vehicle only (left), $1 \mathrm{mg} / \mathrm{ml}$ concentrated EM-X (middle) and $2 \mathrm{mg} / \mathrm{ml}$ concentrated EM-X (right) (A) and KG1a using semi-solid clonogenicity incubated with vehicle only (left) and $2 \mathrm{mg} / \mathrm{ml}$ concentrated EM-X (right) (B). Flow cytometric analysis studying the possible apoptotic potential of concentrated EM-X on KG1a AML cells. Left: vehicle only. Right: $2 \mathrm{mg} / \mathrm{ml}$ of concentrated EM-X (C).
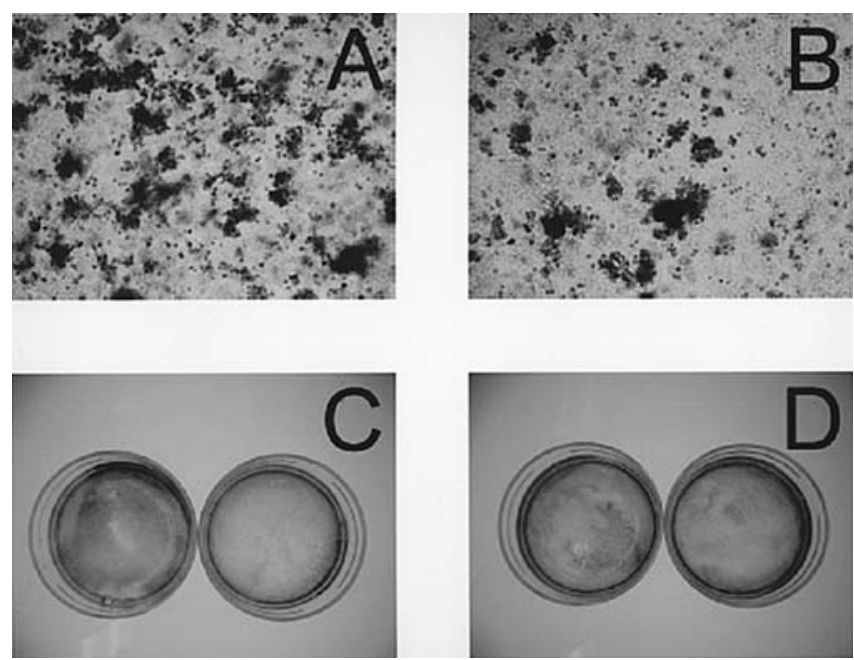

Figure 6. Effects of concentrated EM-X on the regeneration potential of primary cultured bone marrow cells isolated from an AML patient. (A) Microscopic investigation on the AML bone marrow cell treated with vehicle only from the left plate of (C). (B) Microscopic investigation on the AML bone marrow cells treated with $2 \mathrm{mg} / \mathrm{ml}$ of concentrated EM-X from the right plate of $(\mathrm{C})$. No significant difference in the colony formation potential of a non-malignant haematological disorder bone marrow when treated with either vehicle only (left) or $2 \mathrm{mg} / \mathrm{ml}$ of concentrated EM-X (right) (D). 
possible increment of sub- $\mathrm{G}_{0} / \mathrm{G}_{1}$ population from $\mathrm{KG} 1 \mathrm{a}$ cells after concentrated EM-X treatment at a dose of $2 \mathrm{mg} / \mathrm{ml}$ for $24 \mathrm{~h}$. When comparing with vehicle control, a doubling of sub- $\mathrm{G}_{0} / \mathrm{G}_{1}$ population percentage could be detected $(6.37 \%$ vs 13.00\%; Fig. 5C).

\section{Discussion}

EM-X was shown to inhibit the secretion of interleukin-8 at the transcriptional level from A549 human alveolar epithelial cells after treating with hydrogen peroxide or tumour necrotic factor- $\alpha$. EM-X also reduced the iron/ascorbate dependent peroxidation of ox-brain phospholipids in a dose-dependent manner (2). Furthermore, EM-X was also demonstrated to protect the retinal neurons in rats against the injection of $\mathrm{N}$ methyl-D-asparate (NMDA), a glutamate agonist, in vivo (3). In addition, EM-X pretreatment attenuated the loss of nigrostriatal dopaminergic neuron in 6-hydroxydopaminelesion rat model of Parkinson's disease (4). All of these results speculated that the rich content of ascorbic, flavonoids, saponins and vitamin E contents in EM-X could readily attenuate the oxidative stress both in vitro and in vivo.

We have recently reported the growth inhibitory potential of EM-X2 on both K-562 CML and MDA-MB231 breast cancer cells (1). However, to our knowledge, little is known about the possible anti-cancer potential of EM-X. We attempted to use a concentrated formula of EM-X to study its anti-cancer activity as we found that incubating various types of cancer cell lines with the original EM-X fluid did not have significant growth inhibition even up to $30 \%(\mathrm{v} / \mathrm{v})$ of EM-X by volume as compared to EM-X2. Furthermore, the amount of soluble extract found in EM-X2 per ml was found to be much more than that of EM-X (data not shown). As anticipated, concentrated EM-X could possess both antiproliferative and even cytotoxic actions together with reduction in regeneration potential on both Hep3B HCC and KG1a AML cell lines. Similar actions on two primary cultured AML bone marrow samples were also found. The concentrated EM-X also showed selectivity on cancer cells as demonstrated using the SV40 transformed liver epithelial THLE-2 cells and two non-malignant haematological disorder bone marrows. Morphological investigation together with flow cytometry further revealed that concentrated EM-X induced apoptosis of cancer cells. Together with its strong anti-oxidation property, further understanding of the detailed mechanistic pathway should elucidate the underlying working principle of concentrated EM-X on cancer cells.

In vivo animal experimental results suggested that oral administration of EM-X at a dose $16.2 \mathrm{~g} / \mathrm{kg}$ did not have acute toxicity (5). In our case, assuming that an adult has a body weight of $50 \mathrm{~kg}$ and a total blood volume of 51 , the maximum dose of EM-X in the body would be $0.2 \mathrm{~g} / \mathrm{kg}$. Thus theoretically our concentration would still be far from the tested dose. Nude mice xenograft model would possibly explain whether oral administration of concentrated EM-X at the dosage predicted from in vitro data could induce tumour regression in vivo.

There are many naturally occurring products that are reported to be useful in cancer therapy. Of these, many traditional Chinese herbal medicines are well recognized as they have been prescribed for more than five thousand years. These include the anomalous fruit extract of Gleditsia sinensis (6-9), Scutellaria barbata and Radix Sophorae Tonkinensis (10) and Brucea javanica (11). Furthermore, some microbial fermentation products including Phaffia rhodozyma biomass extract are also believed to have anticancer activity in vitro (12). As alternative cancer therapy becomes more acknowledged, we believe that the uses of herbal medicines and microbial fermentation products should provide cancer patients a supplementary treatment in the foreseeable future in additional to conventional chemotherapy (13).

\section{Acknowledgements}

We acknowledge the Hong Kong Polytechnic University (Area of Strategic Development Fund, HKPU), the University Grants Committee (Areas of Excellence Scheme) of the Hong Kong (Project No. AoE/P-10/01) and a Niche Area grant form HKPU. Appreciation is given to Bio-Gene Technology Co., Ltd., and Classic Trend Investment Ltd. for their donation to Haematology Research Funding in Haematology Division, Department of Medicine and Therapeutics, Prince of Wales Hospital (PWH), The Chinese University of Hong Kong (CUHK). Drs F.Y. Lau and C.H. Chui are the honourary tutors kindly offered by Professors J.J.Y. Sung and G.Y.M. Cheng from Department of Medicine and Therapeutics, $\mathrm{PWH}$, CUHK. Special thanks to the EM Research Organization (Okinawa, Japan) and Mr. Fung Man Kit (EM Organic Hong Kong Ltd.) for providing the EM-X and EM-X2 for our experiments. Dr C.H. Chui is supported by the post of 'Senior Research Fellow' offered by Dr J.C.O. Tang from Department of Applied Biology and Chemical Technology, The Hong Kong Polytechnic University. Professor R. Gambari is granted by AIRC and by UE (Interventi Strutturali Obiettivo 2).

\section{References}

1. Chui CH, Cheng GYM, Ke B, Lau FY, Wong RSM, Kok SHL, Fatima S, Cheung F, Cheng $\mathrm{CH}$, Chan ASC and Tang JCO: Growth inhibitory potential of effective microorganism fermentation extract (EM-X) on cancer cells. Int J Mol Med 14: 925-929, 2004.

2. Deiana M, Assunta Dessi M, Ke B, Liang YF, Higa T, Gilmour PS, Jen LS, Rahman I and Aruoma OI: The antioxidant cocktail effective microorganism X (EM-X) inhibits oxidantinduced interleukin- 8 release and the peroxidation of phospholipids in vitro. Biochem Biophys Res Commun 296: 1148-1151, 2002 .

3. Aruoma OI, Moncaster JA, Walsh DT, Gentleman SM, Ke B, Liang YF, Higa T and Jen LS: The antioxidant cocktail, effective microorganism $X(E M-X)$, protects retinal neurons in rats against N-methyl-D-aspartate excitotoxicity in vivo. Free Radic Res 37: 91-97, 2003.

4. Datla KP, Bennett RD, Zbarsky V, Ke B, Liang YF, Higa T, Bahorun T, Aruoma OI and Dexter DT: The antioxidant drink effective microorganism-X (EM-X) pre-treatment attenuates the loss of nigrostriatal dopaminergic neurons in 6-hydroxydopaminelesion rat model of Parkinson's disease. J Pharm Pharmacol 56: 649-654, 2004.

5. Higa T: The Completest Data EM Encyclopedia. Integrated Press, pp182-184, 2000.

6. Chui CH, Tang JCO, Lau FY, Teo ITN, Yau MYC, Wong RSM, Cheng GYM, Ho SKW, Leung TWT, Hui KS, Wong MM, Fatima S, Cheng CH, Cheung F, Tan WQ, Chow LMC, Guo D and Chan ASC: Gleditsia sinensis fruit extract induced growth inhibition involved basic fibroblast growth factor and nitric oxide. Int J Mol Med 13: 169-173, 2004. 
7. Teo ITN, Tang JCO, Chui CH, Cheng GYM, Yau MYC, Lau FY, Wong RSM, Leung TWT, Cheung F, Ho KP, Cheng CH and Chan ASC: Superoxide anion is involved in the early apoptosis mediated by Gleditsia sinensis fruit extract. Int J Mol Med 13: 909-913, 2004.

8. Chui CH, Lau FY, Chan ASC, Cheng GYM, Wong RSM, Lai KB, Kok SHL, Au Yeung TTL, Teo ITN, Yau MYC, Cheung F, Cheng CH and Tang JCO: Gleditsia sinensis fruit extract-induced apoptosis involves changes of reactive oxygen species level, mitochondrial membrane depolarization and caspase 3 activation. Int J Mol Med 15: 539-543, 2005.

9. Cheung F, Chui CH, Chan ASC, Lau FY, Cheng GYM, Wong RSM, Kok SHL, Teo ITN, Cheng CH and Tang JCO: Inhibition of proteasome activity in Gleditsia sinensis fruit extract-mediated apoptosis on human carcinoma cells. Int J Mol Med 16: 925-929, 2005.

10. Chui CH, Lau FY, Tang JCO, Kan KL, Cheng GYM, Wong RSM, Kok SHL, Lai PBS, Ho R, Gambari R and Chan ACS: Activities of fresh juice of Scutellaria barbata and warmed water extract of Radix Sophorae Tonkinensis on anti-proliferation and apoptosis of human cancer cell lines. Int J Mol Med 16: 337-341, 2005.
11. Lau FY, Chui CH, Gambari R, Kok SHL, Kan KL, Cheng GYM, Wong RSM, Teo ITN, Cheng CH, Wan TSK, Chan ASC and Tang JCO: Antiproliferative and apoptosis-inducing activity of Bruces javanica extract on human carcinoma cells. Int J Mol Med 16: 1157-1162, 2005.

12. Teo ITN, Chui CH, Tang JCO, Lau FY, Cheng GYM, Wong RSM, Kok SHL, Cheng CH, Chan ASC and Ho KP: Antiproliferation and induction of cell death of Phaffia rhodozyma (Xanthophyllomyces dendrorhous) extract fermented by brewer malt waste on breast cancer cells. Int J Mol Med 16: 931-936, 2005.

13. Chui CH, Gambari R, Lau FY, Teo ITN, Ho KP, Cheng GYM, Ke B, Higa T, Kok SHL, Chan ASC and Tang JCO: Anti-cancer potential of traditional Chinese herbal medicines and microbial fermentation products. Minerva Biotec 17: 183-191, 2005. 